\title{
Creencias y actitudes de los jóvenes universitarios sevillanos hacia las variedades cultas del español
}

\author{
Juana Santana Marrero* \\ Universidad de Sevilla. Facultad de Filología
}

\begin{abstract}
Resumen
En esta investigación se presentan los resultados iniciales sobre creencias y actitudes de estudiantes universitarios sevillanos hacia las variedades normativas del español, especialmente hacia la suya propia. Para ello se ha seguido la metodología diseñada dentro del Proyecto PRECAVES XXI. Todos los sujetos han cursado estudios de grado o de posgrado relacionados con el ámbito de la lingüística o la lengua española. En concreto, se contrastan dos colectivos: estudiantes que no cuentan con conocimientos especializados sobre las variedades geolectales y sociales del español y estudiantes que sí han adquirido estos saberes en su trayectoria académica. Los datos obtenidos nos ayudarán a conocer qué variedad consideran más prestigiosa y qué grado de aceptación o de rechazo muestran hacia su propio acento $\mathrm{y}$, en menor medida, hacia otros dialectos del mundo hispánico.
\end{abstract}

\footnotetext{
Para correspondencia, dirigirse a: Juana Santana Marrero (jsantana@us.es), Universidad de Sevilla. Facultad de Filología, Departamento de Lengua Española, Lingüística y Teoría de la Literatura. C/ Palos de la Frontera, s/n 41004 - Sevilla, España.
} 
Palabras clave: creencias lingüísticas, actitudes lingüísticas, variedades del español, PRECAVES-XXI, Sevilla, estudiantes universitarios.

\title{
Beliefs and attitudes of young SeVILlian university STUdents TOWARDS THE EDUCATED VARIETIES OF SPANISH
}

\begin{abstract}
This paper presents the initial results concerning the beliefs and attitudes of Sevillian university students towards the normative varieties of Spanish, mainly towards their own variety. The design methodology that we followed is based on the PRECAVES XXI Project. All subjects completed graduate or postgraduate studies related to the field of linguistics or Spanish language. Specifically, two groups were contrasted: students without specialized knowledge about the geolectal and social varieties of Spanish and those who have acquired it in their academic career. The data obtained help us to know which variety is considered most prestigious and how the participants judge their own accent and other dialects of the Hispanic world.
\end{abstract}

Keywords: linguistic beliefs, linguistic attitudes, Spanish varieties, PRECAVES XXI, Seville, university students.

Recibido: 09/01/2018 Aceptado: 06/06/2018

\section{INTRODUCCIÓN ${ }^{1}$}

El Proyecto para el estudio de creencias y actitudes hacia las variedades del español en el siglo XXI (PRECAVES XXI) tiene como finalidad llegar a conocer las percepciones de hablantes de diferentes áreas del mundo panhispánico hacia las ocho modalidades normativas del español (Cestero y Paredes 2015a, Cestero y Paredes 2015b, Paredes y Cestero en prensa): andaluza, andina, canaria, caribeña, castellana, chilena, mexicana y rioplatense. Para ello, las ciudades integrantes trabajan con unos objetivos y

\footnotetext{
1 Esta investigación se desarrolla en el seno del Proyecto Patrones Sociolingüísticos del Español de Sevilla (PASOS-SE) [Ref. FFI2015-68171], financiado por el Ministerio de Economía y Competitividad de España y por el Fondo Europeo de Desarrollo Regional.
} 
una metodología comunes, bajo la coordinación de los profesores Ana María Cestero y Florentino Paredes, de la Universidad de Alcalá, tal y como ha quedado expuesto en el artículo introductorio de este volumen (Cestero y Paredes 2018). En concreto, esta investigación se centrará en los resultados obtenidos del estudio de un conjunto de estudiantes universitarios sevillanos. Siguiendo los objetivos fijados para este monográfico, nos centraremos específicamente en tres aspectos: 1) qué modalidad considera este grupo poblacional como más prestigiosa; 2) cuál es la valoración que hace de su propia variedad, la andaluza ${ }^{2}$ y 3 ) qué consideraciones han suscitado las otras variedades del español.

Como ha apuntado Moreno Fernández (2004 [1998]: 177), los estudios sobre creencias y actitudes constituyen una herramienta eficaz de análisis de las causas que generan los procesos de variación y de cambio lingüístico. Cuando se trata de la modalidad propia, tales investigaciones aportan datos valiosos sobre el grado de apego que los ciudadanos sienten hacia su realidad lingüística, que constituye una de sus principales señas de identidad. Según señalan Ropero y Pérez (1998: 19), una valoración positiva hacia tales recursos contribuye a generar "una actitud de lealtad y orgullo de las propias peculiaridades lingüísticas que llevan al mantenimiento de los usos lingüísticos propios", en todas las situaciones comunicativas, añadimos; mientras que, por el contrario, una percepción negativa del acento propio contribuye a fomentar, en palabras de los autores, "una actitud de descrédito, vergüenza, por la propia forma de hablar y complejo lingüístico de inferioridad, que conducen al abandono voluntario de los propios usos lingüísticos", lo que favorece el empleo de otras normas que se consideran más prestigiosas.

Para el área urbana de Sevilla contamos ya con datos previos sobre las creencias y las actitudes lingüísticas de los ciudadanos hacia su variedad local (Ropero y Pérez 1998). En aquella ocasión se abordaron cuatro puntos fundamentales: 1) las preferencias acerca de la denominación de la modalidad de habla empleada en la ciudad (español / castellano / andaluz / sevillano); 2) la valoración de sus usos lingüísticos y, en estrecha conexión con este parámetro, si los sujetos encuestados consideraban que hablaban bien o mal; 3) el modelo lingüístico que estimaban el mejor o el más correcto; y 4) las actitudes de los sevillanos hacia sus rasgos vernáculos. Para ello, entre los

\footnotetext{
2 PRECAVES XXI cuenta con integrantes de otras ciudades andaluzas, como es el caso de Granada (Manjón-Cabeza Cruz 2018), que aportarán también datos para el conocimiento en profundidad de la percepción de los hablantes de esta variedad dialectal. La heterogeneidad interna del andaluz admite parcelar su estudio en varias áreas regionales.
} 
años 1986 y 1987 se encuestó a un total de 2245 informantes distribuidos según los siguientes parámetros sociales: barrio de residencia dentro de la ciudad de Sevilla, sexo, nivel educativo (alto medio y bajo) y categoría profesional. Entre los resultados obtenidos, destacamos aquellos aspectos que resultan relevantes para nuestro estudio (Ropero y Pérez 1998: 278 y ss.). 1) Predominó una valoración positiva de la modalidad de habla andaluza (se habla bien, 67,6\%, y se habla de forma correcta, 78,0\%). Esto coincide, además, con la percepción de muchos hablantes del hecho diferencial de su variedad dialectal, sin que ello implique que se hable mejor o peor. El factor nivel educativo, señalan los autores, fue significativo, en tanto que los individuos con mayor grado de instrucción reforzaron la actitud positiva, frente a la percepción más negativa de los estadios socioculturales más bajos. 2) La mayoría de los encuestados consideró que el modelo lingüístico más prestigioso, o donde se habla "mejor", es el que se utiliza en Castilla (más del 60,0\%), seguido de la modalidad andaluza. También se observaron porcentajes altos de informantes que no sabían o no contestaban. 3) Un elevado índice de encuestados $(93,9 \%)$ se mostró orgulloso de su modalidad de habla, pues no cambiarían su forma de hablar fuera de Andalucía.

A partir de nuestra investigación tendremos ocasión de comprobar si se sigue estableciendo el modelo de prestigio en el español norteño y, en estrecha conexión con ese punto, qué percepción tiene el hablante sevillano hacia los usos lingüísticos propios. La hipótesis de partida es que los universitarios encuestados consideran la variedad castellana como patrón ejemplar, en convivencia con sentimientos positivos hacia el acento propio. De ser así, encontraríamos aquí una explicación, entre otras posibles, para los procesos de convergencia y divergencia que se dan en el habla de Sevilla.

En lo que respecta al tercer aspecto que nos proponemos estudiar, la valoración de otras variedades del español, hasta el momento solo contamos con datos iniciales sobre la percepción de los acentos canario y castellano (Santana Marrero 2018) en jóvenes sevillanos. En concreto, la pronunciación insular no generó sentimientos de rechazo, frente a la disyuntiva que ocasionó el acento centro-norteño, más apreciado en lo relativo a la proyección social que a aspectos afectivos. Aunque no profundizaremos en esta cuestión, será interesante comprobar qué grado de reconocimiento hacen los universitarios sondeados de las variedades cultas hispanoamericanas. La presuposición inicial es que las modalidades del español americano no generarán índices de reconocimiento elevados y que, en lo relativo al español europeo, el acento centro-norteño se encontrará entre los mejor identificados, precisamente por ser el modelo irradiador de pautas de prestigio en el español de España. 


\section{METODOLOGÍA}

En la concepción mentalista de las creencias y actitudes que aquí manejamos no se observa directamente el comportamiento lingüístico de los sujetos, sino que se indaga en la opinión que suscita en ellos el hecho de habla que se les propone. Para ello es preciso diseñar técnicas de obtención de datos adecuadas que permitan hacer una introspección eficaz en la percepción del individuo y medir sus valoraciones subjetivas. En esta investigación, siguiendo pautas metodológicas comunes a PRECAVES XXI (Cestero y Paredes 2015a, Cestero y Paredes 2015b, Paredes y Cestero 2018), trabajamos con los resultados obtenidos a partir de una encuesta en la que los informantes responden a un conjunto de cuestiones sobre 16 grabaciones, 2 por cada una de las variedades bajo estudio (una que contiene un fragmento de conversación y otra en la que se lee un texto). En el cuestionario se combinan preguntas directas e indirectas, bien planteadas para obtener respuestas cerradas (se ofrecen opciones) o abiertas (que posteriormente se someten a codificación, siguiendo pautas comunes establecidas dentro del Proyecto). Para las cuestiones de tipo indirecto se utilizó la técnica de pares falsos: se presentan adjetivos antónimos que, siguiendo escalas de diferencial semántico, los informantes deben valorar en una gradación de 1 a 6 (la opción 0 representa la ausencia de respuesta).

Para este estudio sondeamos la percepción de 100 estudiantes sevillanos, nacidos y residentes en Sevilla capital o provincia, que estuvieran cursando estudios universitarios con alguna relación con la lingüística y con la lengua española: alumnos de grados en Filología Hispánica, Inglesa o Francesa, del doble grado en Traducción e Interpretación ${ }^{3}$ y estudiantes de posgrado que habían cursado o estaban cursando un máster en Estudios Hispánicos Superiores. Nos planteábamos como objetivo prioritario en esta fase de la investigación general conocer qué valoración tienen los jóvenes de esta comunidad de habla cuyo entorno académico y futuro laboral, este último a menudo ligado a la docencia, están asociados a la reflexión sobre el español y a la difusión de sus variedades cultas. Este sector poblacional adquiere especial relevancia en comunidades de habla meridional como la sevillana, pues los sujetos sondeados tendrán que tomar decisiones acerca de qué acento emplear en su trayectoria universitaria y, fundamentalmente, en su

\footnotetext{
Concretamente, participaron en esta iniciativa los estudiantes que cursaban la materia optativa El español en su variedad.
} 
labor profesional. Si, además, optan por la salida laboral de la enseñanza, serán un referente para sus alumnos en lo que respecta a la variedad que empleen en el aula y a la valoración que les transmitan a los discentes sobre las modalidades dialectales de la lengua española. En concreto, los individuos encuestados se distribuyeron en dos grupos: colectivo 1, formado por 50 estudiantes sin conocimientos especializados sobre variedades del español (estaban cursando primero o segundo de grado en alguna de las Filologías mencionadas); y colectivo 2, 50 estudiantes con tales saberes adquiridos a lo largo de su trayectoria académica (cursaban cursos tercero o cuarto del grado o estudiaban una especialidad de posgrado). De los 100 cuestionarios seleccionados, 57 se realizaron evaluando una voz masculina y 43 una voz femenina ${ }^{4}$.

Para el contraste sociolingüístico tuvimos en cuenta el sexo y la edad de los informantes. En el primer caso trabajamos con las respuestas de 26 hombres y de 74 mujeres. Esta proporción tan desajustada se debe a que en el ámbito de estudios de las Humanidades hay más alumnas matriculadas. En cuanto a la edad, los informantes pertenecen todos a la primera generación, con edades comprendidas entre los 18 y los 34 años. Por tanto, como todos ellos cumplen el requisito de ser jóvenes estudiantes universitarios, no se tendrá en cuenta esta variable para el estudio.

Siempre que sea posible, los resultados se pondrán en relación con dos variables asociadas a la grabación (si la voz evaluada es de hombre o de mujer y si el discurso juzgado es una conversación o un texto leído) y otras dos que constituyen rasgos sociales de los informantes (grado de especialización y sexo).

\section{RESULTADOS: CREENCIAS Y ACTITUDES DE JÓVENES SEVILLANOS HACIA LAS VARIEDADES DEL ESPAÑOL}

A continuación nos ocuparemos de los tres objetivos fijados para este trabajo: 1) detectar qué modalidad de habla creen los universitarios encuestados que tiene mejor consideración, $\mathrm{y}$, consecuentemente, qué puesto le corresponde a

\footnotetext{
4 A pesar de que se diseñó con cuidado un reparto equilibrado, finalmente se produjeron desajustes, debido a que hubo cuestionarios que tuvieron que descartarse, principalmente porque quedaron incompletos.
} 
su propio acento dentro de esta escala; 2) desglosar la percepción que tienen estos hablantes de su propia variedad lingüística; y 3) sondear su grado de reconocimiento y su percepción hacia otros acentos hispánicos diferentes al suyo. Por las limitaciones de espacio con las que contamos, este último aspecto se abordará de forma global.

\subsection{El PRESTIGIO DE LAS VARIEDADES}

Para obtener datos sobre la modalidad de habla que los estudiantes sevillanos encuestados consideran "la mejor" o la más prestigiosa, el cuestionario se inicia con una pregunta general, abierta, formulada en los siguientes términos: En su opinión, ¿dónde cree que se habla mejor el español?

\begin{tabular}{|l|c|}
\hline & $\%$ \\
\hline Castellana & 46,0 \\
\hline Ninguna & 33,0 \\
\hline Andalucía & 8,0 \\
\hline Otros & 5,0 \\
\hline España & 4,0 \\
\hline No contesta & 4,0 \\
\hline
\end{tabular}

Tabla 1. Variedad más prestigiosa

Como se puede apreciar, los informantes consideran que el modelo de buen hablar, el patrón de prestigio lingüístico, está en la variedad castellana. Se repite, por tanto, la tendencia que ya fue registrada hace unos años (Ropero y Pérez 1998: 278 y ss.). No en vano esta modalidad ha sido durante mucho tiempo el punto de partida para conformar el estándar o el modelo de nivelación del español. Las respuestas "reales" que dieron los informantes para identificar la variedad de habla centro-norteña fueron:

\begin{tabular}{|l|c|c|}
\hline & $\mathrm{n}$ & $\%$ \\
\hline Madrid & 17 & 37,0 \\
\hline Valladolid & 8 & 17,4 \\
\hline Castilla & 7 & 15,2 \\
\hline Castilla y León & 3 & 6,5 \\
\hline Castilla la Mancha & 3 & 6,5 \\
\hline
\end{tabular}




\begin{tabular}{|l|c|c|}
\hline Salamanca & 2 & 4,4 \\
\hline Norte de España & 2 & 4,4 \\
\hline Segovia & 1 & 2,2 \\
\hline Toledo & 1 & 2,2 \\
\hline Zaragoza & 1 & 2,2 \\
\hline Septentrional & 1 & 2,2 \\
\hline TOTAL n & 46 & \\
\hline
\end{tabular}

Tabla 2. Denominación de la variedad castellana

De todas las contestaciones obtenidas, la más abundante fue "Madrid". No es de extrañar que se ubique el modelo de prestigio lingüístico en la capital del país, por el hecho de ser el centro neurálgico de la nación en el que se concentra la mayor parte de la actividad política, económica y cultural. Su presencia constante en los medios, desde donde se retransmite gran parte de los eventos públicos, alimenta también esta percepción. La segunda respuesta más significativa fue "Valladolid". Esta es una creencia compartida por informantes toledanos (Molina Martos 1998: 63) y madrileños (Yraola 2014: 587).

No obstante, a pesar de esta tendencia preferente según la cual existe una jerarquía de prestigio entre unas variedades y otras, algo está cambiando, pues registramos también un índice bastante elevado de respuestas que entienden que en las distintas áreas hispanohablantes se habla de forma diferente, pero no mejor ni peor. Este planteamiento, que se sitúa en la línea de la política lingüística panhispánica actual de la Asociación de Academias de la Lengua Española, parece que va poco a poco calando entre los sevillanos más jóvenes, aunque de momento está en una posición de desventaja con respecto a la opinión de que en el norte se habla mejor que en el sur.

A bastante distancia de las opciones mayoritarias, también se registraron respuestas que colocan a la variedad andaluza como el acento que tiene una mejor consideración. No obstante, a juzgar por nuestros datos, no puede decirse que sea la pauta predominante en los colectivos seleccionados. 


\begin{tabular}{|c|c|c|c|c|c|c|c|c|c|c|c|c|c|c|}
\hline & & \multicolumn{2}{|c|}{ Castellana } & \multicolumn{2}{|c|}{ Ninguna } & \multicolumn{2}{|c|}{ Andaluza } & \multicolumn{2}{|c|}{ España } & \multicolumn{2}{|c|}{ Otros } & \multicolumn{2}{|c|}{\begin{tabular}{|c|} 
No \\
contesta
\end{tabular}} & \multirow{2}{*}{$\begin{array}{c}\text { TOTAL } \\
n\end{array}$} \\
\hline & & $\mathrm{n}$ & $\%$ & $\mathrm{n}$ & $\%$ & $\mathrm{n}$ & $\%$ & $\mathrm{n}$ & $\%$ & $\mathrm{n}$ & $\%$ & $\mathrm{n}$ & $\%$ & \\
\hline \multirow{2}{*}{ Colectivo } & $\begin{array}{l}\text { Sin } \\
\text { formación }\end{array}$ & 29 & 58,0 & 9 & 20,0 & 6 & 12,0 & 4 & 8,0 & 2 & 4,0 & 0 & 0,0 & 50 \\
\hline & \begin{tabular}{|l|} 
Con \\
formación
\end{tabular} & 17 & 34,0 & 24 & 48,0 & 2 & 4,0 & 0 & 0,0 & 3 & 6,0 & 4 & 8,0 & 50 \\
\hline \multirow{2}{*}{ Sexo } & Hombres & 11 & 42,3 & 8 & 30,8 & 2 & 7,7 & 2 & 7,7 & 2 & 7,7 & 1 & 3,9 & 26 \\
\hline & Mujeres & 35 & 47,3 & 25 & 33,8 & 6 & 8,1 & 2 & 2,7 & 3 & 4,1 & 3 & 4,1 & 74 \\
\hline
\end{tabular}

Tabla 3. Variedad más prestigiosa según grado de especialización y según sexo

Al contrastar las tres opciones mayoritarias con el grado de especialización de los encuestados se observa que este fue un factor que condicionó la opinión de los informantes. En efecto, aquellos estudiantes que habían recibido formación acerca de la variación dialectal y social del español fueron más conscientes de que la diferencia geolectal no va ligada a relaciones de jerarquía entre unas modalidades y otras. Por su parte, los alumnos sin formación especializada se inclinan más hacia la creencia de que la variedad castellana representa el modelo de buen hablar. Así se puede comprobar en la tabla 3, con 28 puntos de diferencia entre un colectivo y otro. Este grupo de universitarios sin formación especializada destaca también por aferrarse más a la idea del andaluz como el acento mejor considerado. Por último, la variable sexo solo arrojó resultados significativos en la preferencia por la modalidad andaluza, algo más acentuada en las mujeres, aunque la frecuencia absoluta tan baja que obtuvo esta respuesta no permite obtener conclusiones significativas.

\subsection{Percepción DE LA VARIEDAD PROPIA}

Un primer paso para abordar en profundidad cómo perciben los sujetos encuestados su modalidad de habla es discriminar aquellas grabaciones en las que reconocieron su acento. Cuando no fue así, esos informantes estaban emitiendo juicios sobre otras variedades y, por tanto, sus respuestas no son relevantes para esta investigación. 


\begin{tabular}{|l|c|c|}
\hline & $\mathrm{n}$ & $\%$ \\
\hline Exacta & 141 & 70,5 \\
\hline Errónea & 13 & 6,5 \\
\hline Otra (España) & 45 & 22,5 \\
\hline No contesta & 1 & 0,5 \\
\hline TOTAL $\mathrm{n}$ & 200 & \\
\hline
\end{tabular}

Tabla 4. Identificación de la variedad andaluza

Como era de esperar, la mayor parte de los individuos identificó de forma exacta su acento, bien señalando que se trataba de "Sevilla", o bien relacionando la grabación con "Andalucía" o, en menor medida, con alguna zona concreta de esta región como "Cádiz", "Málaga" o "Almería". Por otro lado, las respuestas erróneas asociaron la voz juzgada con un grupo de áreas heterogéneas: "Madrid", "México", "De la Meseta", "Colombia", "Ecuador", "Argentina", "Castilla La Mancha" y "Extremadura". Ante estos datos, y, especialmente, ante la contestación errónea mayoritaria de "Madrid", nos preguntamos en qué medida el tipo de discurso podía haber influido en la percepción del hablante, es decir, si el hecho de que la grabación escuchada fuera una conversación no planificada o un texto leído podía haber condicionado su respuesta.

\begin{tabular}{|c|c|c|c|c|c|c|c|}
\hline & \multirow{2}{*}{\multicolumn{2}{|c|}{ Identificación }} & \multicolumn{2}{|c|}{ Lectura } & \multicolumn{2}{|c|}{ Conversación } & \multirow{2}{*}{$\begin{array}{c}\text { SUBTOTAL } \\
\mathrm{n} \\
\end{array}$} \\
\hline & & & $\mathrm{n}$ & $\%$ & $\mathrm{n}$ & $\%$ & \\
\hline \multicolumn{3}{|c|}{ Exacta } & 56 & 39,7 & 85 & 60,3 & 141 \\
\hline \multirow{8}{*}{ Errónea } & Madrid & 5 & \multirow{7}{*}{11} & \multirow{8}{*}{84,6} & \multirow{7}{*}{0} & \multirow{8}{*}{15,4} & \multirow{8}{*}{13} \\
\hline & México & 1 & & & & & \\
\hline & De la Meseta & 1 & & & & & \\
\hline & Colombia & 1 & & & & & \\
\hline & Ecuador & 1 & & & & & \\
\hline & Argentina & 1 & & & & & \\
\hline & Castilla la Mancha & 1 & & & & & \\
\hline & Extremadura & 2 & 0 & & 2 & & \\
\hline
\end{tabular}

Tabla 5. Identificación de la variedad andaluza según tipo de discurso 
En efecto, como intuíamos, el tipo de discurso fue un factor influyente. La mayor parte de las identificaciones exactas se dieron a partir de la conversación (60,3\%), donde el acento se siente más cercano y parecido al propio. Por otro lado, la lectura, que favorece una dicción algo más esmerada $\mathrm{y}$, en este sentido, más alejada de la pronunciación natural y cotidiana, propició el error de reconocimiento (la identificación correcta desciende al $39,7 \%$ ). De ahí su equiparación con las variedades castellana o mexicana, por ejemplo, con mayor tendencia a conservar las consonantes implosivas, por destacar algún rasgo. En lo que respecta a las confusiones que se asentaron en la conversación, no solo fueron minoritarias sino que se asociaron con un acento también meridional, el extremeño, que tiene estrechas conexiones con el andaluz occidental.

Una vez que hemos comprobado que la mayoría de los informantes reconoció acertadamente las grabaciones andaluzas, resulta interesante saber en qué medida se sintió identificado con ellas. A este respecto es preciso señalar que el hombre y la mujer que prestaron su voz para realizar esta investigación eran sevillanos. Este aspecto puede favorecer el grado de cercanía o de empatía del sujeto encuestado hacia la voz evaluada.

\begin{tabular}{|c|c|c|c|c|c|}
\hline & & & & & \\
\hline \multirow{3}{*}{$\begin{array}{l}\text { No identidad } \\
\text { o similar }\end{array}$} & Totalmente diferente & 3 & \multirow{3}{*}{16} & 2,1 & \multirow{3}{*}{11,3} \\
\hline & Bastante diferente & 1 & & 0,7 & \\
\hline & Ligeramente diferente & 12 & & 8,5 & \\
\hline \multirow{3}{*}{$\begin{array}{l}\text { Identidad } \\
\text { o similar }\end{array}$} & Ligeramente igual & 23 & \multirow{3}{*}{125} & 16,3 & \multirow{3}{*}{88,7} \\
\hline & Bastante igual & 59 & & 41,8 & \\
\hline & Totalmente idéntica & 43 & & 30,5 & \\
\hline \multicolumn{2}{|l|}{ TOTAL } & \multicolumn{4}{|c|}{141} \\
\hline
\end{tabular}

Tabla 6. Identidad con las voces evaluadas

Como se puede comprobar, la mayor parte de los informantes se sintió identificado con las voces escuchadas $(88,7 \%)$. De hecho, el grupo más destacado fue el de estudiantes que entendieron que ese acento era "bastante igual" al suyo (41,8\%). Pensamos que los índices de identidad plena no fueron más elevados por la gran heterogeneidad interna que existe en el andaluz en general y en el habla de Sevilla en particular (Santana Marrero 2016, Santana Marrero 2017, Santana Marrero en prensa).

Una vez más creemos que el tipo de discurso puede haber influido en la percepción de los sujetos encuestados y que pudieron sentirse más identificados con el acento de la conversación que con el de la lectura. 


\begin{tabular}{|l|c|c|c|c|}
\hline \multirow{2}{*}{} & \multicolumn{2}{|c|}{ No identidad o similar } & \multicolumn{2}{c|}{ Identidad o similar } \\
\cline { 2 - 5 } & $\mathrm{n}$ & $\%$ & $\mathrm{n}$ & $\%$ \\
\hline Conversación & 8 & 50,0 & 77 & 61,6 \\
\hline Lectura & 8 & 50,0 & 48 & 38,4 \\
\hline SUBTOTAL n & \multicolumn{2}{|c|}{16} & \multicolumn{2}{c|}{125} \\
\hline
\end{tabular}

Tabla 7. Identidad con la variedad propia según tipo de discurso

Los datos de la tabla 7 corroboran la hipótesis inicial: partiendo de que la mayoría de los individuos asoció su acento con el de la voz escuchada, este porcentaje se incrementó en 23 puntos cuando se trataba de un fragmento sin planificación previa, donde prevalece una pronunciación más natural.

A partir de ahora, para la valoración de la modalidad andaluza trabajaremos solamente con una parte del material, concretamente con las 141 grabaciones que fueron identificadas de forma exacta.

\subsubsection{Valoración directa}

En este apartado nos proponemos averiguar qué opinan los informantes sobre el acento que se ha empleado en las grabaciones. En concreto, se centrarán directamente en los usos lingüísticos y los valorarán conforme a una serie de parámetros que están distribuidos en dos bloques: afectivos y cognitivos.

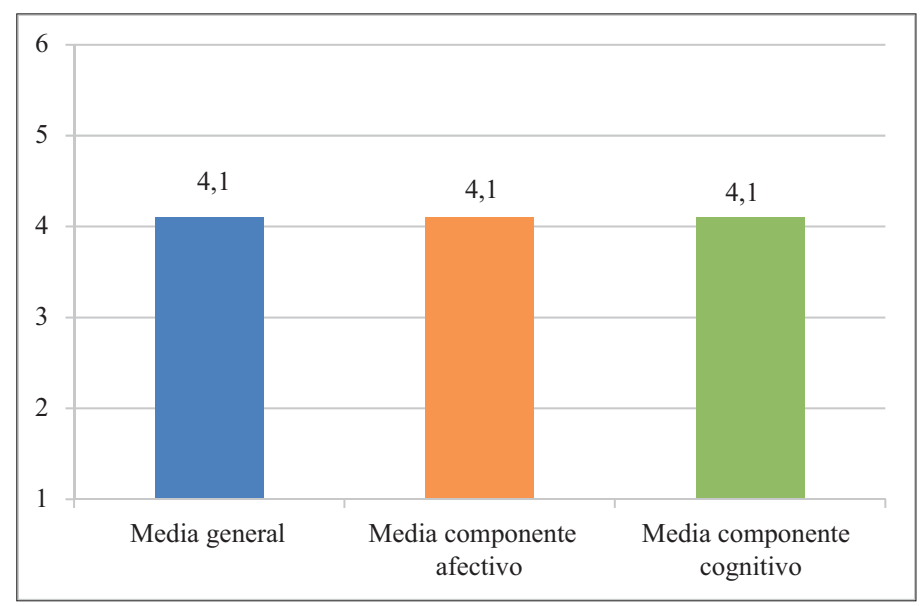

Gráfico 1. Medias de la valoración directa 
De forma general, la percepción de los estudiantes encuestados sobre su variedad de habla es positiva, superando ligeramente las zonas intermedias. En lo que respecta a la influencia de los factores de variación que hemos considerado para esta investigación, grado de especialización, sexo del informante, voz evaluada y tipo de discurso, este último parámetro es el único que ha influido en los valores medios registrados ${ }^{5}$.

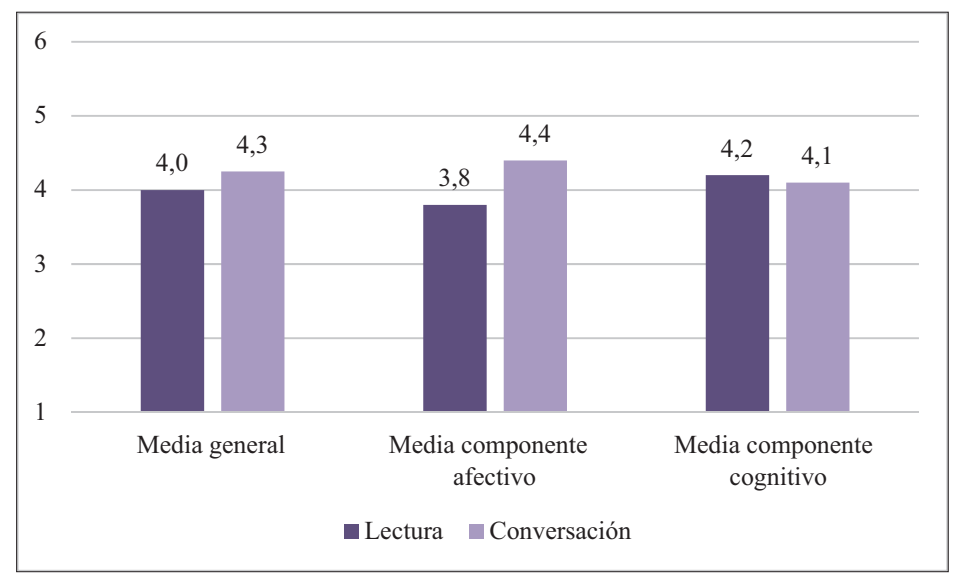

Gráfico 2. Medias de la valoración directa según tipo de discurso

Como hemos venido observando, el hecho de que la grabación juzgada procediera de una conversación o de un texto leído ha repercutido en la percepción de los informantes. En esta ocasión, el índice de afectividad en general aumenta cuando se trata de un discurso más ligado a la espontaneidad, el conversacional. Recuérdese que este era también el tipo de texto con el que los sujetos se sentían más identificados.

5 Dadas las limitaciones de espacio con las que contamos, solo podemos mostrar aquellas figuras que aportan datos relevantes para el análisis. 


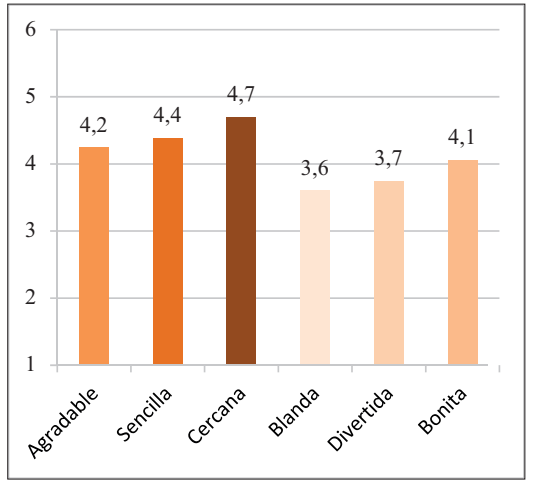

Gráfico 3. El componente afectivo

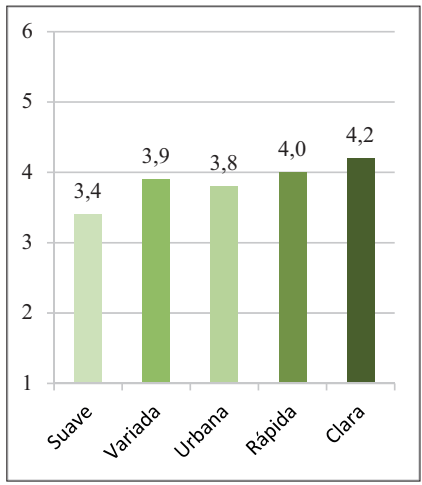

Gráfico 4. El componente cognitivo

Si desglosamos los componentes afectivo y cognitivo, no es de extrañar que, tratándose de su propio acento, los informantes viertan sobre él valores emocionales positivos como su carácter agradable, su sencillez, su belleza y, especialmente, su cercanía. En el apartado cognitivo, con valores en general algo más bajos que el afectivo, resulta interesante el tímido refuerzo que ha recibido la claridad del acento. A pesar de que la pronunciación andaluza se asocia a menudo a la falta de inteligibilidad (Carbonero Cano 2001: 1516), las creencias de los estudiantes encuestados apuntan hacia la idea de que es un acento que, con sus particularidades, permite que el mensaje sea recibido y comprendido con éxito por el receptor. Tenemos, en definitiva, una valoración intermedia de los sujetos hacia su variedad local: positiva en términos generales, pero con reservas porque no se sitúa en las posiciones más altas de la escala.

Para completar este apartado vamos a señalar aquellos rasgos lingüísticos que de forma más concreta recibieron mejor y peor consideración entre los informantes ${ }^{6}$.

6 Las variadas respuestas obtenidas fueron codificadas atendiendo a los siguientes parámetros: rasgos fónicos, gramaticales, léxicos, pragmático-discursivos, otros (contestaciones que no tenían cabida en los apartados anteriores), ninguno (cuando lo señalaron explícitamente) y no contesta. 


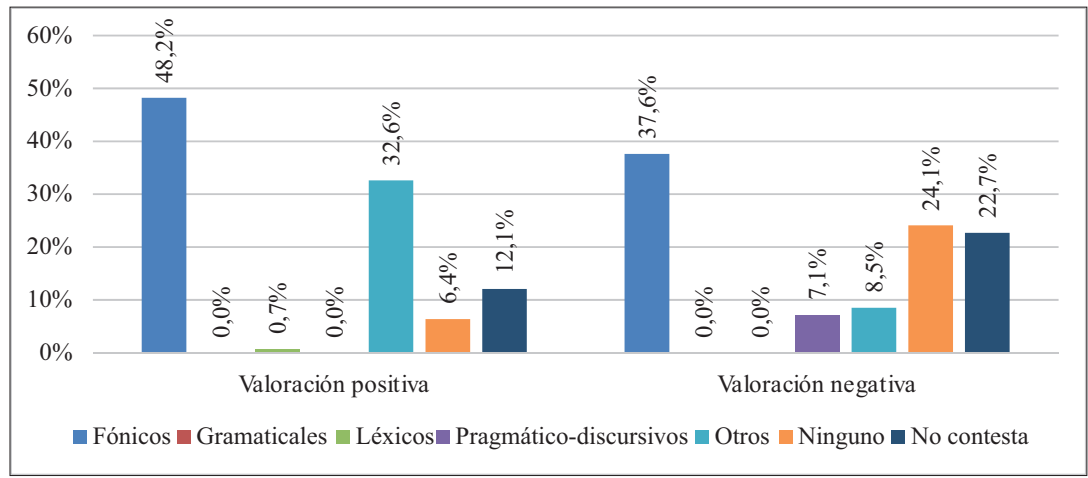

Gráfico 5. Rasgos lingüísticos con valoración positiva y negativa

Como era de esperar, en ambos bloques los rasgos que acuden de forma más nítida a la mente de los individuos encuestados son los que tienen que ver con la pronunciación. En la parte positiva se distinguen aspectos genéricos ("la tonalidad", "el acento", "la claridad") o se alude a fenómenos puntuales, generalmente asociados a la pronunciación vernácula ("la aspiración de las consonantes", "seseo", "la pronunciación de la s y de la ch"). Lo mismo sucede en la parte negativa ("a veces va demasiado rápido", "la falta de vocalización", "seseo"). Nótese que hay rasgos, como el seseo, que entran en ambos bloques. Esto es solo una mínima muestra de la lucha interna que se está gestando en la ciudad de Sevilla entre el seseo y la distinción s/z (Santana Marrero 2016, Santana Marrero 2017, Santana Marrero en prensa). El primero es el rasgo vernáculo y el segundo refleja la tendencia a seguir parámetros más prestigiosos, mimetizando pautas de pronunciación de la zona centro-norteña. Como veíamos arriba, esta es la pronunciación que muchos hablantes siguen considerando como modelo de buen hablar. En este sentido, los datos de la norma culta sevillana muestran la preferencia por la escisión fonemática (Santana Marrero 2016). En el sociolecto bajo (Santana Marrero 2017, Santana Marrero en prensa) prevalece la variante dialectal, aunque las mujeres muestran un fuerte apego a la solución convergente. 


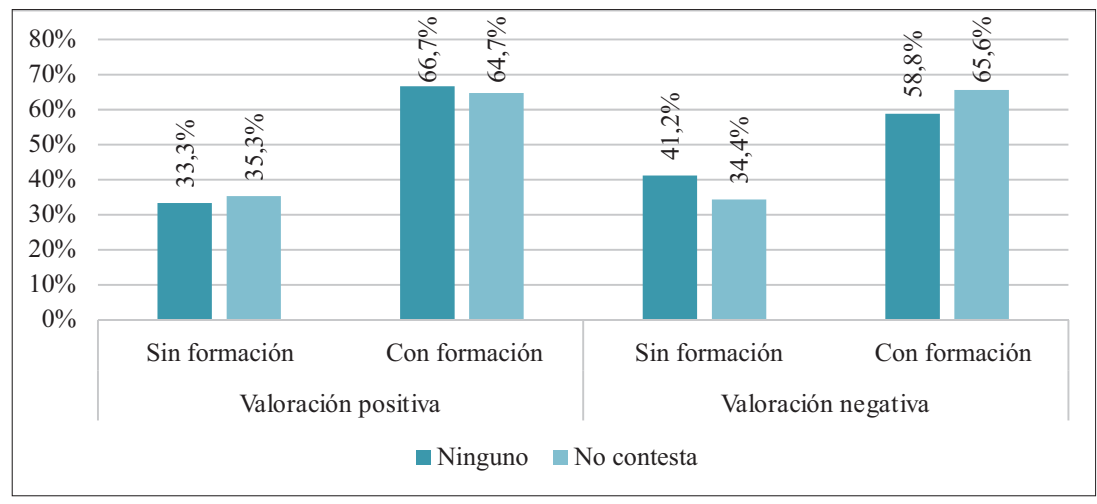

Gráfico 6. Respuestas "Ninguno" y "No contesta” según grado de especialización

En esta ocasión, el colectivo encuestado actuó como factor influyente en los resultados. En concreto, los estudiantes con formación reforzaron aquellas respuestas que van en una línea menos dogmática: bien señalando que ninguno de los rasgos de la grabación escuchada les parecía mejor o peor, o bien por el incremento de ausencia de respuestas tanto en las valoraciones positivas como en las negativas. En este sentido se percibe que la instrucción académica recibida acerca de las diferencias diatópicas y diastráticas en el español ha contribuido a fortalecer una visión de la variedad como algo natural, inherente a la lengua, y no como un aspecto censurable que implique un desvío con respecto a un patrón ejemplar.

\subsubsection{Valoración indirecta a través de la persona que habla}

En este nuevo bloque de contenidos analizamos las creencias sobre la variedad andaluza que emitieron los informantes a partir de las características sociales y personales del sujeto de la grabación. Es decir, se les pidió a los encuestados que hicieran valoraciones sobre el estatus social y sobre una serie de cualidades individuales a partir del acento de la voz evaluada. Por tanto, se estaba juzgando, aunque de forma indirecta, su manera de hablar.

\subsubsection{Estatus social}

En este apartado se sondearon tres parámetros que guardan estrecha relación: puesto de trabajo, nivel de ingresos y nivel de estudio. 


\begin{tabular}{|c|c|c|c|}
\hline & & $\mathrm{n}$ & $\%$ \\
\hline \multirow{4}{*}{$\begin{array}{l}\text { Puesto de trabajo } \\
\text { (Media } 1,8)\end{array}$} & Poco cualificado & 41 & 29,1 \\
\hline & Bien cualificado & 87 & 61,7 \\
\hline & Altamente cualificado & 12 & 8,5 \\
\hline & No contesta & 1 & 0,7 \\
\hline \multirow{4}{*}{$\begin{array}{l}\text { Nivel de ingresos } \\
\text { (Media 1,9) }\end{array}$} & Bajo & 29 & 20,6 \\
\hline & Medio & 98 & 69,5 \\
\hline & Alto & 13 & 9,2 \\
\hline & No contesta & 1 & 0,7 \\
\hline \multirow{5}{*}{$\begin{array}{l}\text { Nivel de estudios } \\
\text { (Media 3,0) }\end{array}$} & Sin estudios & 5 & 3,6 \\
\hline & Primarios & 26 & 18,4 \\
\hline & Secundarios & 76 & 53,9 \\
\hline & Universitarios & 33 & 23,4 \\
\hline & No contesta & 1 & 0,7 \\
\hline \multicolumn{2}{|c|}{ TOTAL n } & \multicolumn{2}{|c|}{141} \\
\hline
\end{tabular}

Tabla 8. Valoración indirecta: estatus social

En términos generales, el acento andaluz inspira a los sujetos encuestados creencias positivas acerca de la posición social y la formación de la persona que habla, pero no en la escala máxima de la valoración. Si desglosamos los datos, la mayoría de los informantes relacionó su pronunciación con personas que tienen un trabajo bien cualificado $(61,7 \%)$, un nivel de ingresos medio $(69,5 \%)$ y estudios secundarios $(53,9 \%)$. Sin embargo, no hay que perder de vista que los índices asociados a las escalas inferiores (trabajo poco cualificado, nivel de ingresos bajo y sin estudios o con estudios primarios) fueron en casi todos los casos más elevados que los que se atribuyeron a los puntos más altos de la escala, a excepción de la formación, donde la instrucción universitaria $(23,4 \%)$ superó ligeramente las posiciones más bajas $(22,0 \%)$. Las medias también nos muestran unas valoraciones moderadas que, si bien no son negativas, sí dejan entrever que, en términos generales, el acento andaluz no se asocia a los sectores sociales más altos.

Al contrastar estos datos con los factores que estamos considerando para nuestra investigación, apreciamos la existencia de ciertas influencias de los rasgos que guardan relación con las características de la grabación: la voz evaluada y el tipo de discurso. 


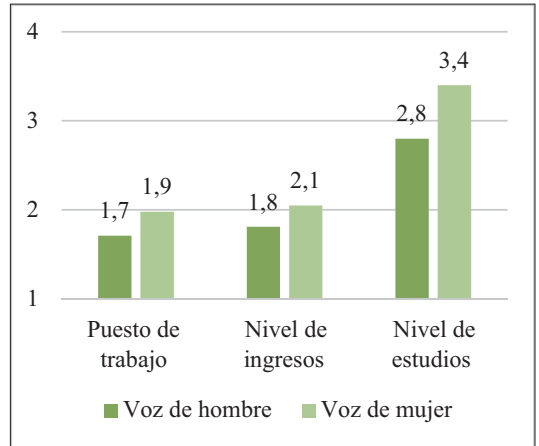

Gráfico 7. Estatus social según voz evaluada

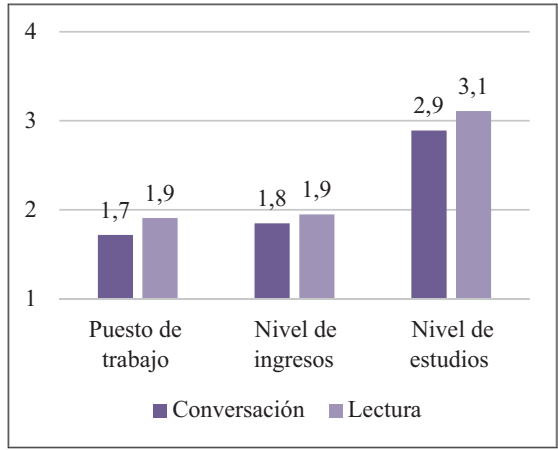

Gráfico 8. Estatus social según tipo de discurso

En efecto, en todos los casos las creencias fueron más positivas cuando se juzgó una voz femenina y, especialmente, cuando se trataba de un texto leído. Este segundo dato nos dice que cuanto más natural es el acento y, como es previsible, con una pronunciación vernácula más marcada, menos consideración social se le atribuye a la persona que lo habla. $\mathrm{O}$, lo que es lo mismo, una pronunciación más esmerada y, probablemente, con los rasgos dialectales más suavizados, que se acerca más a los patrones conservadores y normativos de pronunciación del español, se asoció en mayor medida con mejoras en la posición social.

\subsubsection{Características personales}

En este subapartado vamos a analizar qué creencias sobre el grado de inteligencia, de simpatía, de cercanía, de cultura y de educación ${ }^{7}$ suscita en los informantes el acento andaluz de las voces grabadas.

7 No en el sentido de grado de instrucción, sino de buenos modales y cumplimiento de las normas sociales: educado / maleducado. 


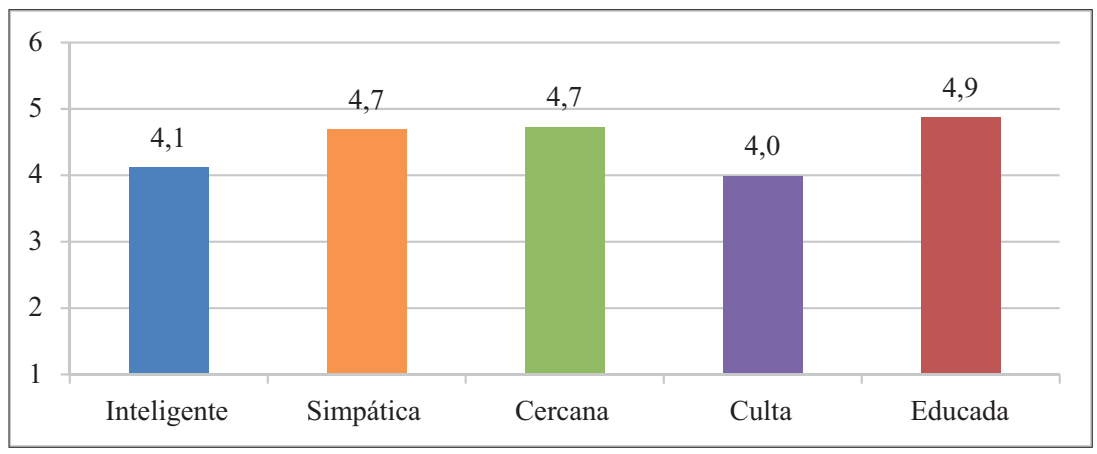

Gráfico 9. Valoración indirecta: características personales

En el plano personal, las valoraciones ascienden considerablemente con respecto a las que repercuten directamente sobre la pronunciación dialectal (gráficos 1, 3 y 4). El acento propio, por tanto, despierta creencias favorables sobre los sujetos que lo emplean, especialmente en lo que se refiere a que son personas cercanas, simpáticas y con buenos modales o educadas. Nótese cómo los valores que bajan ligeramente, aunque el resultado global es positivo, son los relativos a la inteligencia y a la cultura. Estos, en cierto modo, son los parámetros que, dentro de los considerados, pueden tener una mayor proyección social: el estatus de una persona depende en gran medida de su grado de inteligencia y de su cultura (le permitirá acceder a un nivel más alto de estudios y, consecuentemente, obtener una mejor ocupación laboral que le reporte mayor número de ingresos). Esto puede interpretarse, por tanto, conectando con lo que veíamos en el apartado anterior, como el mantenimiento de cierto recelo en lo que respecta a la conexión del acento andaluz con el ascenso social.

En esta ocasión se detectaron influencias, aunque mínimas, de tres de los cuatro factores considerados para esta investigación. 


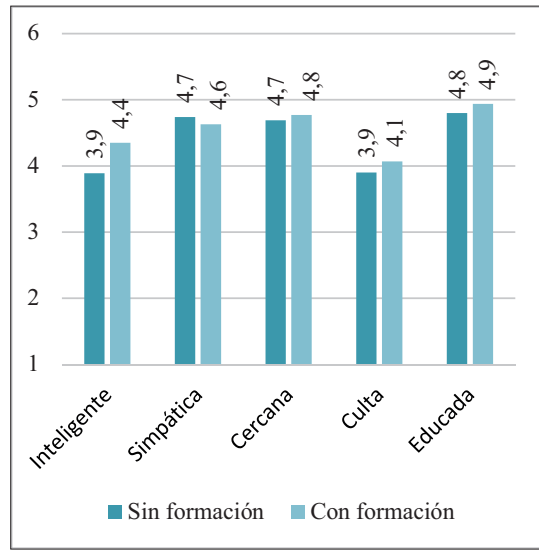

Gráfico 10. Características personales según grado de especialización

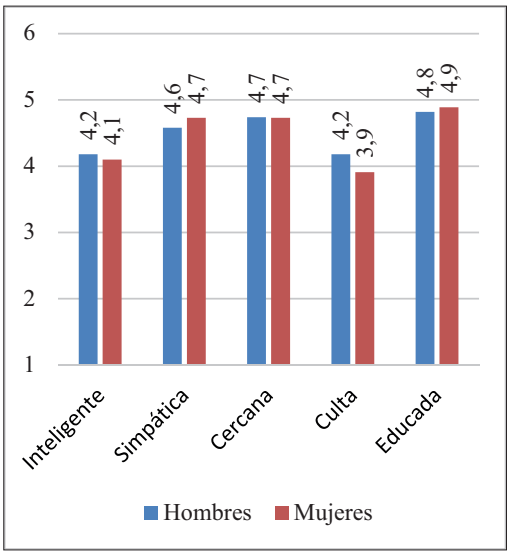

Gráfico 11. Características personales según sexo

En lo que respecta a los rasgos que identifican a los informantes, el grado de formación ha influido en los ítems de inteligencia y cultura. Se observa que la especialización del sujeto contribuye positivamente a reforzar estos conceptos que, como hemos señalado, tienen mayor proyección social, aunque se trata de apreciaciones mínimas.

Por su parte, las mujeres presentaron diferencias con respecto a los hombres en el parámetro del grado de cultura. Atendiendo a nuestros resultados, para ellas el acento andaluz se asocia en mayor medida con una persona inculta, quizá por su tendencia a sentirse más identificadas con las pautas conservadoras y normativas procedentes de la variedad norteña (López Morales 2004 [1989]: 127-130, Villena Ponsoda 2012: 43-45, Santana Marrero 2016: 274-277, Santana Marrero 2017, Santana Marrero en prensa). 


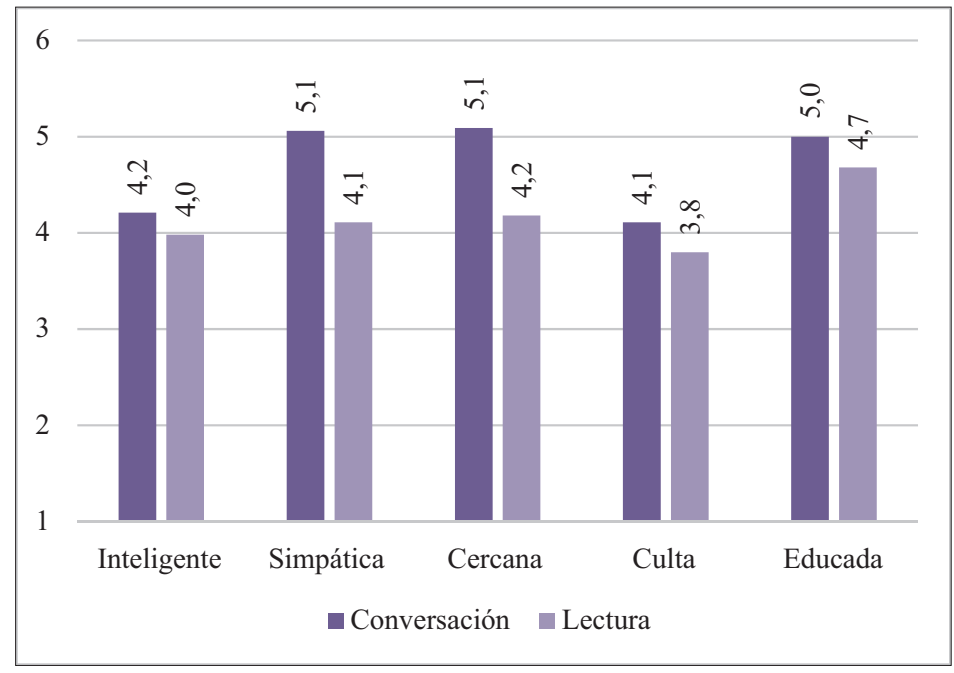

Gráfico 12. Características personales según tipo de discurso

En último lugar, los resultados obtenidos a partir del tipo de discurso van en una dirección distinta a las hipótesis que se han venido confirmando a lo largo de este trabajo. Si el texto leído, al que se le presupone una pronunciación más esmerada y más cercana a los rasgos conservadores y normativos, genera creencias relativas a un mayor estatus social de las personas, es previsible que suscite también unos valores más elevados en las cualidades personales que tienen más proyección social: inteligencia y cultura. Sin embargo, esta hipótesis no se confirma con nuestros datos. Las voces procedentes de conversación, y no de la lectura, incrementaron las creencias positivas sobre estos parámetros. Sí se confirmó, sin embargo, el hecho de que la pronunciación vernácula más marcada esté asociada a un incremento, esta vez más significativo, de las valoraciones positivas en cualidades que tienen menos repercusión social: la simpatía, la cercanía y el tener buenos modales.

Siguiendo en el plano de las características personales, cuando se les preguntó a los sujetos encuestados su opinión sobre los andaluces, predominaron las respuestas favorables $(94 / 141,66,7 \%)$. Estas se centraron principalmente en que son buenas personas y trabajadoras; se destacó también su amabilidad, su carácter agradable y divertido, su generosidad, su cercanía y su carácter abierto y positivo ("personas maravillosas y divertidas", "divertidas, simpáticas y agradables así como cercanas", "sociales y abiertas", "muy trabajadora, amables en general y generosos. Divertidos y dicharacheros"). En el lado opuesto, las cualidades censurables 
fueron mínimas (2/141, 1,4\%). En ellas se recriminaba el hecho de que las personas juzgadas no hablaban de forma adecuada ("algunas personas que viven en esa zona no hablan demasiado bien", "no se suelen explicar muy bien").

\subsubsection{Valoración indirecta a través de la región y la cultura}

Un último aspecto que hemos sometido a evaluación es el tipo de creencias sobre la región y la cultura andaluzas que generó en los sujetos encuestados su propia modalidad de habla. En lo que respecta a la región se valora si es avanzada o retrasada, si es divertida o aburrida, si les resulta familiar o extraña y si les parece que es bonita o fea. En cuanto a su cultura, se sondean los parámetros relativos a su nivel de innovación, riqueza, cercanía y grado de interés. Comenzamos exponiendo los valores medios obtenidos.

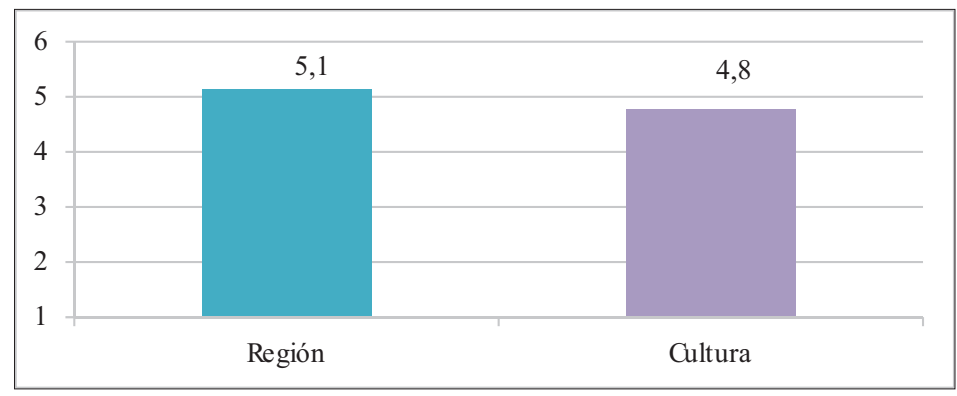

Gráfico 13. Medias de la valoración indirecta a través de la región y la cultura

Como se puede observar, los sevillanos encuestados ponen de manifiesto una percepción muy positiva de la zona en la que viven y de su patrimonio cultural. Veamos de forma desglosada cada uno de estos componentes. 


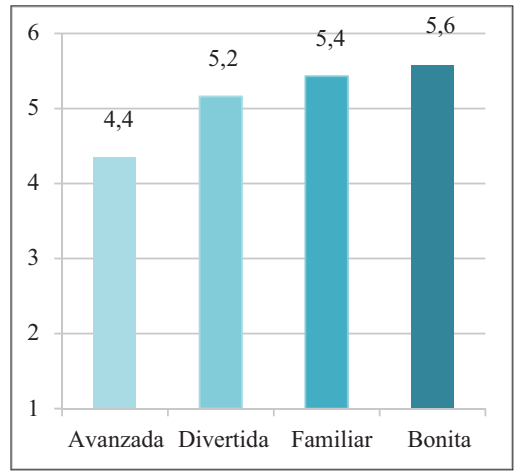

Gráfico 14. La región

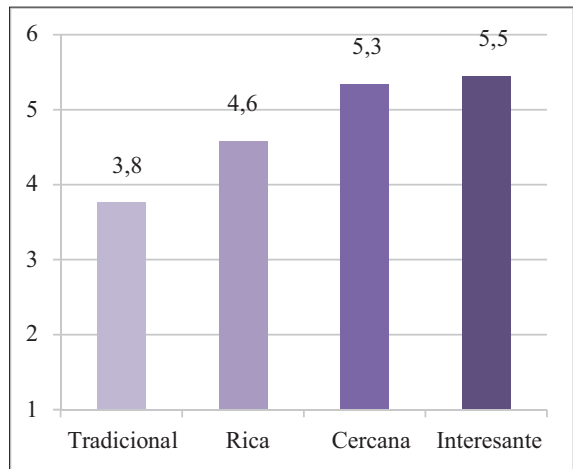

Gráfico 15. La cultura

En esta ocasión destacamos el descenso que sufre el ítem relativo al avance, en el bloque de la región. En esta misma línea de ligera bajada se sitúa el parámetro que se refiere a si su cultura es tradicional o innovadora. A este respecto, interpretamos que los estudiantes sevillanos encuestados son conscientes de que Andalucía sigue estando más rezagada que otras comunidades españolas en lo que respecta al desarrollo económico y tecnológico y a las corrientes de innovación cultural.

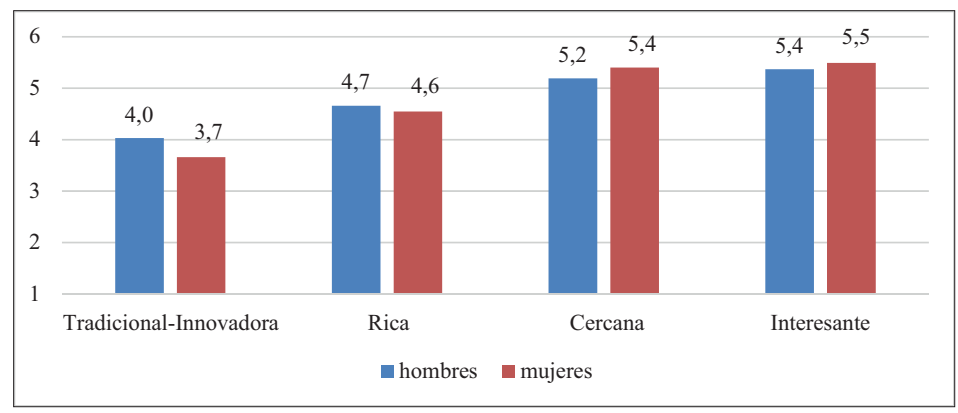

Gráfico 16. Valoración de la cultura según sexo

De los factores tenidos en cuenta como posibles causas de variación en los resultados solo hemos detectado una ligera diferencia entre hombres y mujeres con respecto al grado de innovación, en el bloque de la cultura. Las féminas reafirmaron más su posición sobre el carácter tradicional de los valores culturales de Andalucía. 


\subsection{IDENTIFICACIÓN Y VALORACIÓN DEL RESTO DE LAS VARIEDADES}

Para terminar nuestro análisis haremos una aproximación general a la capacidad que han demostrado los sujetos encuestados para identificar otras variedades normativas distintas a la suya y qué han suscitado en ellos esos acentos. Del total de 1600 grabaciones que componen la muestra (recuérdese que cada informante valoró 16 audios), en esta ocasión estudiaremos 1400, pues quedarán excluidas las 200 correspondientes al andaluz.

\begin{tabular}{|l|c|c|}
\hline & $\mathrm{n}$ & $\%$ \\
\hline Exacta & 540 & 38,6 \\
\hline Errónea & 475 & 33,9 \\
\hline Otra (Hispanoamérica / España ${ }^{8}$ ) & 336 & 24,0 \\
\hline No contesta & 49 & 3,5 \\
\hline TOTAL $\mathrm{n}$ & \multicolumn{2}{|c|}{1400} \\
\hline
\end{tabular}

Tabla 9. Identificación de otras variedades

A pesar de que, en términos relativos, el número de aciertos no es elevado, se obtuvo un porcentaje ligeramente más significativo que el de identificaciones erróneas.

\begin{tabular}{|c|c|c|c|c|c|c|c|c|c|}
\hline \multirow{2}{*}{ Colectivo } & \multicolumn{2}{|c|}{ Exacta } & \multicolumn{2}{|c|}{ Errónea } & \multicolumn{2}{|c|}{ Otra } & \multicolumn{2}{|c|}{ No contesta } & \multirow{2}{*}{$\begin{array}{c}\text { SUBTOTAL } \\
\mathrm{n}\end{array}$} \\
\hline & $\mathrm{n}$ & $\%$ & $\mathrm{n}$ & $\%$ & $\mathrm{n}$ & $\%$ & $\mathrm{n}$ & $\%$ & \\
\hline $\mathrm{C} 1$ & 274 & 39,1 & 260 & 37,1 & 156 & 22,3 & 10 & 1,4 & 700 \\
\hline $\mathrm{C} 2$ & 266 & 38,0 & 215 & 30,7 & 180 & 25,7 & 39 & 5,6 & 700 \\
\hline
\end{tabular}

Tabla 10. Identificación de otras variedades según colectivo

La distribución por colectivo puso de manifiesto que, si bien los estudiantes con conocimientos especializados registraron un mayor número de identificaciones correctas, también es cierto que se mostraron más cautos, en tanto que dieron más respuestas genéricas (España o Hispanoamérica) y dejaron de contestar en más ocasiones.

8 Aquellos casos en los que el encuestado identificó un acento hispanoamericano como perteneciente a España o, por el contrario, o en los que relacionó uno español con Hispanoamérica, fueron considerados respuestas erróneas. 
A partir de ahora nos interesarán las respuestas en las que los informantes reconocieron el acento de las grabaciones, para ver qué juicios emitieron sobre cada una de ellas.

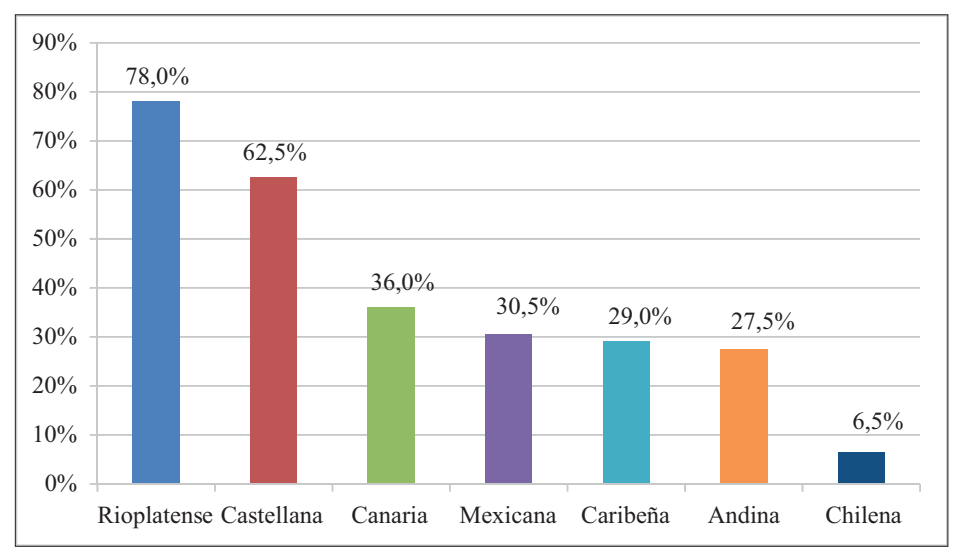

Gráfico 17. Grado de identificación de otras variedades

De todas las modalidades consideradas, exceptuando la andaluza, hubo dos acentos que los jóvenes sevillanos reconocieron con más facilidad: en primer lugar la variedad rioplatense (156 grabaciones) y en segundo término, la castellana (125 audios). Los dialectos canario, mexicano, caribeño y andino obtuvieron índices de reconocimiento con porcentajes moderados. El acento chileno fue el que, con diferencia, les resultó más extraño a los encuestados, con solo 13 casos de identificación exacta.

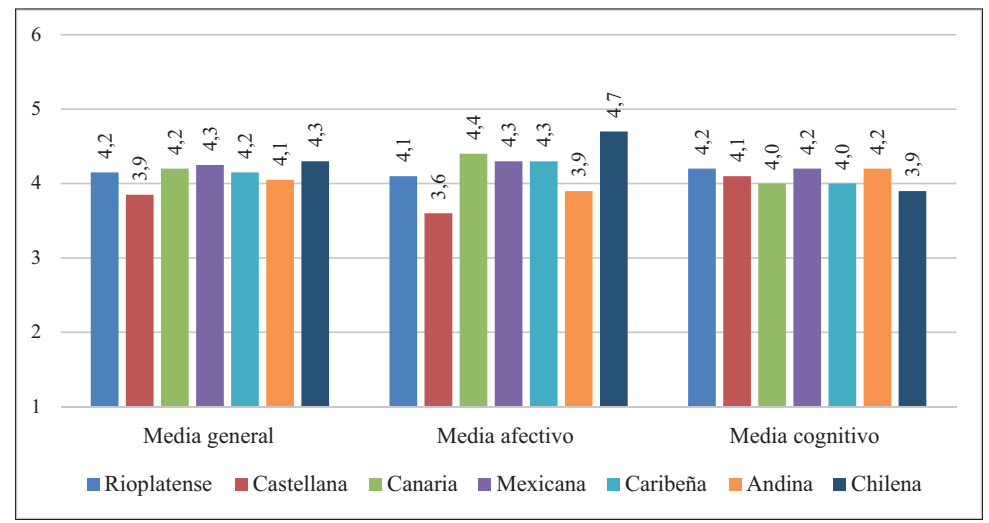

Gráfico 18. Valoración directa de otras variedades 
La consideración general de estas variedades dialectales se sitúa en todos los casos por la zona de los índices positivos, superando ligeramente la franja intermedia. Los valores afectivos y los cognitivos presentan resultados bastante similares. De los resultados expuestos en el gráfico 18 destacamos el descenso que experimenta la modalidad castellana en el nivel afectivo, aspecto que ya habíamos observado en otra ocasión (Santana Marrero 2018). Pueden presuponerse algunos tópicos que enfrentan al norte y al sur: se intuye la tendencia a pensar que la modalidad centro-norteña no es tan apreciada por los sevillanos, de forma paralela al rechazo que genera el acento andaluz en los madrileños (Yraola 2014: 599-600).

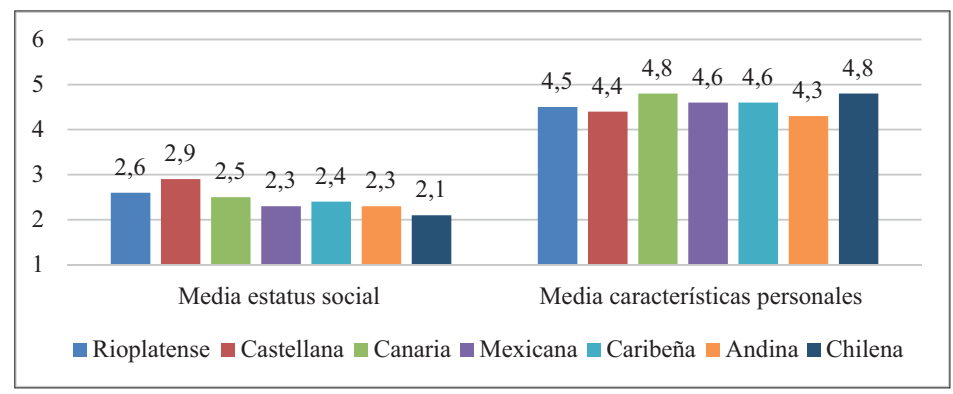

Gráfico 19. Valoración indirecta de otras variedades: estatus social y características personales

Para el estatus social, los juicios sobre el grado de instrucción o el nivel adquisitivo que han suscitado los distintos acentos hispánicos en los estudiantes sevillanos revelan valoraciones bastante equilibradas. Destaca tímidamente la consideración algo más positiva de la modalidad centronorteña, pues fue el acento que despertó en los estudiantes sevillanos una proyección social algo más alta. Recordemos que fue la variedad que los sujetos encuestados identificaron mayoritariamente con el modelo de buen hablar. En cuanto a las cualidades personales, el índice general es bastante homogéneo, con valoraciones positivas que superan en todos los casos la zona intermedia.

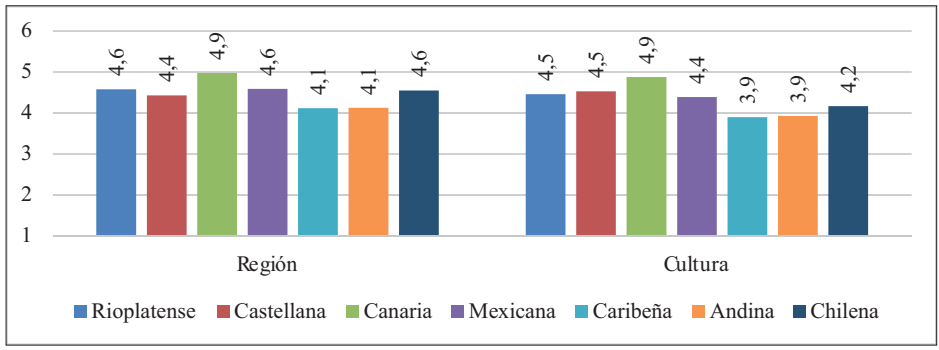

Gráfico 20. Valoración indirecta de otras variedades: región y cultura 
Por último, los juicios emitidos sobre la región y la cultura de las personas que utilizan estos acentos despertaron en términos generales puntuaciones bastante altas. Sobresale de forma apenas perceptible la modalidad de habla canaria, cuya zona y hábitos culturales fueron los mejor valorados.

\section{CONCLUSIONES}

En este trabajo hemos obtenido resultados relevantes en relación con los tres aspectos bajo estudio: qué variedad consideran los sujetos analizados que es la más prestigiosa, qué valoración hacen del acento propio y qué percepción tienen de otros acentos hispánicos. Se partió del sondeo de un grupo de estudiantes universitarios sevillanos cuyos estudios de grado o posgrado guardaban relación con la lengua española, distribuidos según su nivel de conocimiento de las variedades geográficas y sociales del español. Estos informantes percibieron, de forma mayoritaria, que existen jerarquías entre las distintas variedades del español y, en concreto, prevalece entre ellos la idea de que la modalidad centro-norteña es el modelo de buen hablar. Ahora bien, el sentimiento de inferioridad lingüística que puede inferirse de este dato está en estrecha competencia con la idea de que la variación diatópica y diastrática del español no conlleva relaciones jerárquicas de superioridad e inferioridad entre los distintos acentos. Esta segunda tendencia recibió su principal empuje entre los estudiantes con conocimientos especializados sobre las variedades de la lengua. Se puede concluir que se mantienen latentes las dos alternativas, que ya se perciben desde hace varias décadas. La creencia entre los jóvenes sevillanos encuestados de que el modelo del buen hablar está en el dialecto centro-norteño puede fomentar actitudes de rechazo hacia la propia modalidad de habla, especialmente en situaciones comunicativas formales como la enseñanza y los medios de comunicación. Hubo pocos informantes que consideraran al andaluz como el modelo más prestigioso.

En lo que respecta a la valoración directa del acento propio, en términos generales el análisis arrojó creencias positivas, aunque no en las zonas más altas de la escala propuesta. La mayoría de los sujetos reconoció la pronunciación andaluza y se sintió en gran parte identificados con ella, preferentemente en las grabaciones procedentes de conversación, donde es de esperar que la dicción sea más natural y espontánea. Los componentes afectivo y el cognitivo recibieron juicios bastante similares. En este último cabe destacar el ligero ascenso que experimentó el rasgo de la claridad. 
Este dato revela que los estudiantes fueron en cierta medida conscientes de que emplear rasgos vernáculos no impide la transmisión de un mensaje que sea entendido de forma plena por el receptor. Pudimos percibir también una situación de contradicción con respecto a algunos fenómenos de pronunciación locales, como el seseo, que recibieron consideraciones positivas y negativas. Este dato deja traslucir la lucha interna que se da actualmente en la ciudad de Sevilla, donde conviven realizaciones dialectales como el patrón seseante con usos convergentes como la distinción s/z más propios de la variedad castellana que, recordemos, sigue siendo considerada por muchos sujetos el modelo de pronunciación prestigiosa.

En la valoración del estatus social a partir del acento andaluz de la voz evaluada volvió a repetirse el patrón predominante en esta investigación: prevalecen las creencias positivas, aunque no se sitúan en la escala máxima. En términos generales esta variedad dialectal fue relacionada con individuos que cuentan con un trabajo bien cualificado, un nivel de ingresos medio y estudios de grado secundario, aunque los parámetros más bajos del rango propuesto también obtuvieron índices representativos. Las percepciones más positivas se asociaron a la voz femenina y, especialmente, a la lectura. Es decir, una pronunciación algo más esmerada, donde los rasgos dialectales quedan ligeramente más difuminados, impulsó la conexión con un estatus social más alto. Se percibe, por tanto, la lucha entre el apego a lo local y el prestigio de la variedad castellana.

Cuando el análisis giró hacia la esfera más personal, es decir, qué cualidades individuales sugerían en los informantes el acento evaluado, los índices subieron de manera significativa, principalmente en lo que se refiere a parámetros como la simpatía, la cercanía y los buenos modales. Esto se notó especialmente cuando se trataba de una conversación, donde el discurso se siente como más natural. No obstante, los valores bajaron algo en aquellos parámetros que tienen una relación más estrecha con la proyección social de la persona: inteligencia y cultura. Este descenso fue más representativo entre las mujeres.

Por su parte, la consideración de la región y la cultura andaluzas a partir del acento de las voces evaluadas obtuvo los índices más altos de la encuesta. Se advirtió una tímida bajada en el carácter avanzado de la región y en la innovación cultural. En este sentido, los informantes, recordemos que son jóvenes, consideran que Andalucía sigue siendo una zona que está a la zaga del avance tecnológico y de las innovaciones culturales que están presentes en otras regiones españolas.

En definitiva, la percepción que tienen los universitarios sevillanos seleccionados para esta investigación conlleva una actitud intermedia entre la valoración positiva de lo propio, aunque a menudo no en el grado máximo 
de la escala, y la rendición a lo ajeno, concretamente al acento de la variedad castellana. No en vano sigue perviviendo la idea de que se habla mejor en el norte que en el sur. Estas creencias tienen un reflejo inmediato no solo en la pronunciación de la calle, sino también en la de los profesionales de la educación, de los medios de comunicación y de los políticos locales y autonómicos, en cuyas intervenciones se percibe una lucha constante entre el apego y el rechazo a lo vernáculo. Los resultados de nuestra investigación justifican la pervivencia en la actualidad de procesos de variación interna en el habla local de Sevilla. Al mismo tiempo, es previsible que esta lucha tenga eco en el futuro profesional de los encuestados, a buen seguro en muchos casos ligado a la enseñanza del español.

Finalmente, en cuanto al grado de identificación de otros acentos, las variedades rioplatense y castellana fueron las reconocidas con más facilidad por los jóvenes sevillanos. A este respecto, el colectivo de estudiantes con conocimientos especializados fue el que más habilidad reveló para reconocer variedades distintas a la suya, aunque también se mostró más cauto, con un mayor número de ausencia de respuestas. En términos generales, las valoraciones que hicieron sobre los otros acentos del mundo hispánico fueron bastante homogéneas, con puntuaciones más elevadas en las cualidades personales y en la consideración de la región y la cultura. Destacamos la percepción de la modalidad castellana, que recibió la valoración más baja en el componente afectivo, mientras que obtuvo una puntuación ligeramente superior en el plano del estatus social. Habrá que seguir indagando con más profundidad en este aspecto, para ver de qué manera se conjugan la consideración de mayor prestigio que obtuvo el acento centro-norteño, con una previsible asociación positiva con respecto a la proyección social, y el tímido descenso que experimentó esa pronunciación en el plano más emocional entre los encuestados. Finalmente, la región y la cultura canarias recibieron una valoración ligeramente más alta que el resto de las áreas consideradas.

\section{REFERENCIAS BIBLIOGRÁFICAS}

Carbonero Cano, Pedro. 2001. Habla andaluza, identidad cultural y medios de comunicación. En María Auxiliadora Castillo Carballo y Juan Manuel García Platero (coords.). Las hablas andaluzas: problemas y perspectivas, pp. 13-23. Sevilla: Signatura Ediciones.

Cestero, Ana María y Florentino Paredes. 2015 a. Creencias y actitudes hacia las variedades normativas del español actual: primeros resultados del Proyecto PRECAVES- XXI. Spanish in context 12/2, 255-279. 
2015b. Creencias y actitudes hacia las variedades del español en el siglo XXI: avance de un proyecto de investigación. En Demerval da Hora, Juliene Lopes R. Pedrosa y Rubens M. Lucena (eds.). ALFAL 50 anos: contribuições para os estudos linguísticos e filológicos, pp. 652-683. João Pessoa: Ideia.

2018. Creencias y actitudes hacia las variedades cultas del español actual: el proyecto PRECAVES-XXI, Boletín de Filología (este volumen).

López Morales, Humberto. 2004 [1989]. Sociolingüística, 2a edición. Madrid: Gredos.

Manjón-CABeza Cruz, Antonio. 2018. Creencias y actitudes de los jóvenes universitarios granadinos hacia las variedades cultas del español Boletín de Filología (este volumen).

Molina Martos, Isabel. 1998. La fonética de Toledo. Contexto geográfico y social. Alcalá de Henares: Universidad de Alcalá.

Moreno Fernández, Francisco. 2004 [1998]. Principios de sociolingüística y sociología del lenguaje, $2^{\mathrm{a}}$ edición. Barcelona: Ariel Lingüística.

Paredes, Florentino y Ana María Cestero. En prensa. Percepciones de las variedades cultas del español por parte de hablantes del centro-norte de España según los datos del Proyecto PRECAVES- XXI: el español ejemplar y la variedad propia. Oralia 21/1.

Ropero, Miguel y Francisco Javier Pérez. 1998. Análisis estadístico-sociológico de los comportamientos lingüísticos en la ciudad de Sevilla. Sociolingüística Andaluza 11. Sevilla: Publicaciones de la Universidad de Sevilla.

Santana Marrero, Juana. 2016. Seseo, ceceo y distinción en el sociolecto alto de la ciudad de Sevilla: nuevos datos a partir de los materiales de PRESEEA. Boletín de Filología de la Universidad de Chile 51/2: 255-280.

2017. Variación de las realizaciones de $/ \theta^{\mathrm{s}} /$ en el sociolecto bajo de la ciudad de Sevilla: datos de PRESEEA-SE. Lingüistica en la Red. Monográfico XV. Procesos de variación y cambio en el español de España. Estudios sobre corpus PRESEEA [en línea]. Disponible en: http://www.linred.es/monograficos_pdf/LR-monografico15-articulo2.pdf [Consulta 26/12/2017].

2018. Creencias y actitudes de jóvenes universitarios sevillanos hacia las variedades normativas del español de España: andaluza, canaria y castellana. Pragmática Sociocultural / Sociocultural Pragmatics 6/1 [en línea]. Disponible en: https://www. degruyter.com/printahead/j/soprag [Consulta 12/6/2018].

En prensa. Factores externos e internos influyentes en la variación de $/ \theta^{\mathrm{s}} /$ en la ciudad de Sevilla. Analecta Malacitana XXXIX.

Villena Ponsoda, JuAn AndRÉs. 2012. Patrones sociolingüísticos del español de Andalucía. En: Juan Andrés Villena Ponsoda y Antonio Manuel Ávila Muñoz (eds.). Estudios sobre el español de Málaga. Pronunciación, vocabulario y sintaxis, pp. 27-66. Málaga: Sarriá.

Yraola, Aitor. 2014. Actitudes lingüísticas en España. En: Ana Beatriz Chiquito y Miguel Ángel Quesada Pacheco (eds.). Bergen Language and Linguistic Studies 5. Actitudes lingüisticas de los hispanohablantes hacia el idioma español y sus variantes, pp. 551-636 [en línea]. Disponible en http://dx.doi.org/10.15845/bells.v5i0.685 [Consulta 28/12/2017]. 